\title{
Ivan Illich: La combativa inocencia y la lucidez de un hombre inquieto
}

Marcos Santos GómeZ

Universidad de Granada

RESUMEN: Ivan Illich es una figura polémica en el mundo de la pedagogía por su propuesta de "desescolarizar" la sociedad. Sus ideas siguen teniendo mucha vigencia para enfrentar las relaciones autoritarias en la sociedad y la mercantilización de la educación.

ABSTRACT: Ivan Illich is a polemic figure in the world of pedagogy due to his proposal of "deschooling" society. His ideas are important to confront authoritarian relations in society and to face the mercantilization of the educative systems.

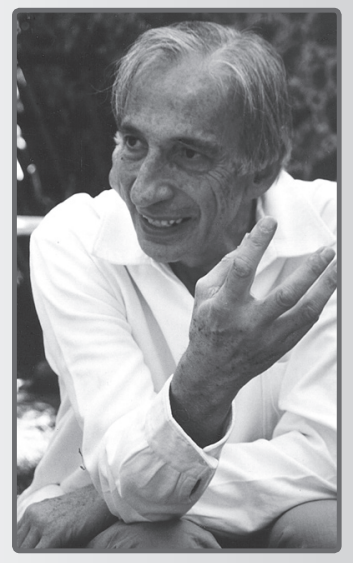




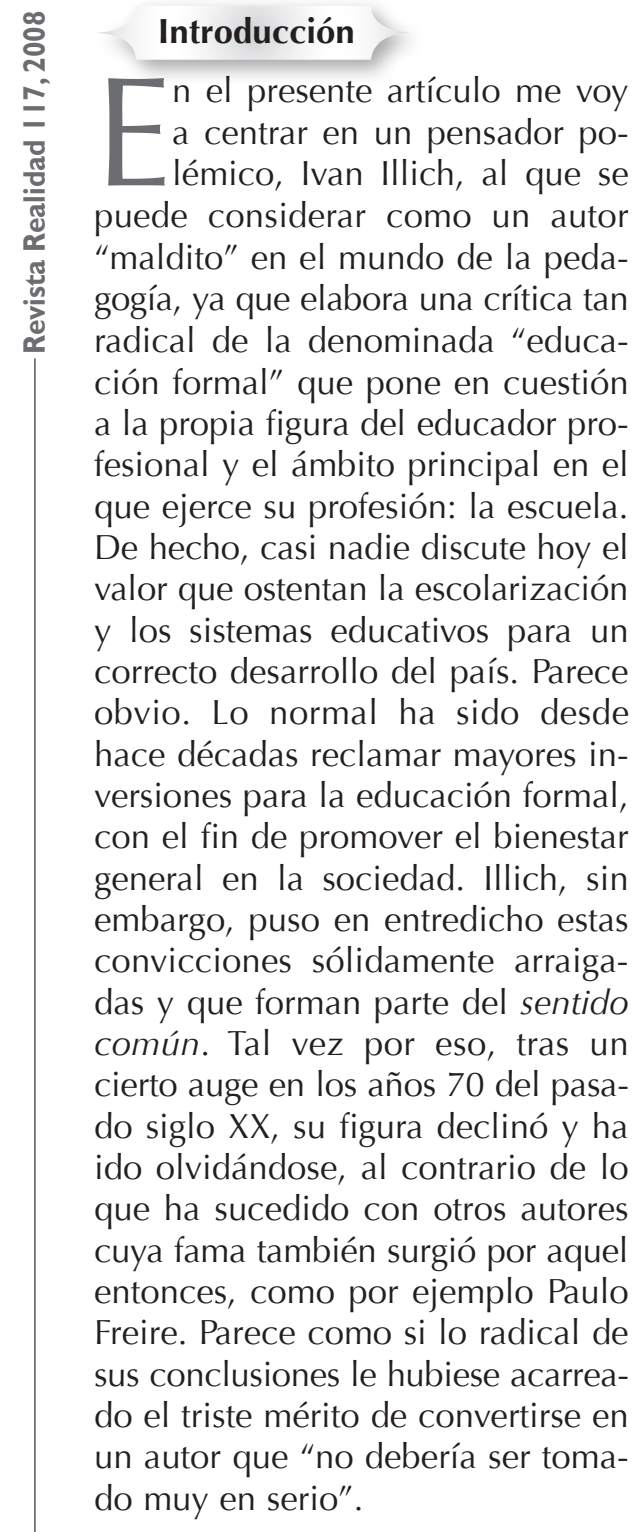

Sin embargo, creo que se obra mal cuando a Illich se le considera sólo por sus conclusiones, sin atenderse seriamente a sus razones y argumentos. Pienso que si procuramos eludir el rechazo visceral que en algunos acarrea su peculiar concepción, tal vez sería posible extraer ciertas ideas positivas para la pedagogía. Su contundente crítica y perspectiva utópica nos sirven, si accedemos a dialogar con ellas, para repensar nuestra sociedad y abordar el a veces ignorado problema de los fines que persigue toda acción educativa, lejos de una perspectiva meramente técnica tan sólo interesada en los medios. Nuestra sociedad administrada, como la denominó Horkheimer, en la que la razón se reduce a saber instrumental que manipula la realidad con automatismo y a ciegas, engloba enormes peligros que se vienen anunciando desde hace casi un siglo. Es con esta advertencia de los autores de la primera Escuela de Francfort, o de sugerentes filósofos de la historia como Walter Benjamin, con la que entronca Illich, pero a la que añade un talante desbordantemente optimista.

También me podría aventurar incluso a afirmar que, aún con la apariencia de propugnar soluciones educativas descabelladas, Illich puede estar planteándonos estrategias bastante cercanas a hechos que ya se dan en la realidad educativa. Es curioso; es como si estuviéramos más cerca de aquello que propuso de lo que suponemos (iy a pesar del rechazo que suele provocar!). Porque, como afirma un buen estudioso de su pensamiento, Antoni Tort: "Hoy las posibilidades de aprendizaje han roto los límites escolares y una educación más respetuosa 
con el deseo de aprender implica necesariamente la aceptación de entornos diferenciados. El futuro educativo apunta, pues, a una fusión y diversificación de estructuras, redes e instituciones educativas, incluida la escuela. Para algunos, a inicios del siglo XXI, estamos muy lejos de la tesis desescolarizadoras; para otros, estamos mucho más cerca $^{1}$ ".

En cualquier caso, en las líneas que siguen, voy a intentar desarroIlar, al menos, todo el potencial que tiene la filosofía de Illich para hacernos pensar, evitando los prejuicios que puedan poner en guardia ante su pensamiento. Su visión profundamente perturbadora, que, como voy a explicar, considero de una combativa inocencia, nos puede servir para entender mejor algo tan poliédrico como es la educación.

\section{La combativa inocencia}

van Illich nos conduce a una concepción de la acción educativa que podemos calificar de combativa. Sin duda, esto es lógico si tenemos en cuenta desde qué lugar desarrolló lo más importante de su labor, o sea, América Latina ${ }^{2}$. Tal vez porque la irracionalidad y la injusticia estructural de nuestro mundo golpean allí con mayor fuerza, mostrando con evidencia la necesidad de que toda educación que pretenda ser útil se haga cargo de ello. Se puede decir que la perentoria necesidad de una praxis transgresora se manifiesta mejor en las realidades de fuerte opresión, porque salta a la vista. En el denominado Tercer Mundo, puede verse cómo la injusticia ya no es sólo una mera cuestión puntual, sino estructural, que afecta al propio sistema en sí, a su naturaleza.

Pero, además, deseo enfatizar que la concepción combativa de Illich le viene gracias a una suerte de transformación en la mirada, en el punto de vista desde el que analiza y observa la sociedad, que se asemeja al de un niño. Es decir, manteniéndose bien inmerso en la sociedad, sin perder nunca su contacto con la realidad, es capaz de salirse de ella para analizarla con extrañeza, lo cual implica una explosiva inocencia ${ }^{3}$, en la que se subvierten los juicios acerca del mundo. Lo obvio se torna no tan obvio, y, al contrario, lo raro se manifiesta como lo obvio. Esta subversión en la mirada es, ya de por sí, evidentemente combativa.

Así, pues, cuando Ivan Illich aborda el estudio de la sociedad contemporánea y de sus instituciones, realiza una descripción desde fuera, desde la mencionada posición ingenua que le ayuda a ver las cosas que suelen pasar desapercibidas por el hábito y los prejuicios. Su originalidad a la hora de estudiar la institución escolar, como cuando estudia otras instituciones contemporáneas, viene dada por un enfoque 
descriptivo-fenomenológico que lo dota de esta efervescente inocencia. Así, afirma: "Trato de describir sencillamente lo que veo, como si fuera un marciano, lo que constituye el concepto de escolaridad. Es un proceso de clasificación de toda la sociedad en grupos, en gremios alrededor de otro personaje, a quien se le da muchos nombres diferentes, pero que esencialmente es distinto de los demás personajes reunidos porque participó muchas más horas en estas reuniones específicas por edades" ${ }^{\prime 4}$.

Lo primero a lo que le conduce esta ingenuidad en la mirada es a una percepción muy negativa del progreso tecnológico. Su crítica a este aspecto de la modernidad no es ni mucho menos un hecho solitario y corresponde a un sentimiento bastante generalizado a lo largo del dramático siglo XX y que hoy ha cuajado, por ejemplo, en los movimientos ecologistas a los cuales precedió en numerosos planteamientos. La Escuela de Francfort, el freudomarxismo, los movimientos contraculturales de los años sesenta y setenta, etc., Ilegaron a conclusiones similares desde enfoques algo diferentes. Todas ellas se resumen en la idea de que nos hemos alejado de un modelo humano de sociedad. Es decir, vivimos existencias deshumanizadas que, en el fondo, nadie habría querido vivir, si hubiera podido elegirlo. A partir de aquí, la dificultad teórica, estrechamente conectada con la práctica, estriba en la definición de en qué consiste lo humano.
En Illich lo humano es algo abierto, lejos de todo esencialismo, (éste es un punto clave de su pensamiento) y no definido previamente, pero que requiere de una sociedad apta que permita expresarlo. Por eso, su crítica radical a la escuela se relaciona, sobre todo, con el cuestionamiento a un modelo de vida que imposibilite esta búsqueda que podemos denominar existencial. Las difusas alternativas que este autor a veces sugiere procuran aproximarse a un modelo de sociedad que sí haga posible el intercambio de conocimiento y la comunicación entre las personas; es decir, a un tipo de organización social en el que nuestras existencias se realizarían dialogando. Pero, insisto, siendo consecuente con el carácter utópico de su pensamiento, jamás detalla con exactitud el dibujo de esa futura y deseable salud humana.

En los temas que estudió Illich a lo largo de su obra se refleja la vastedad de los campos de aplicación de sus teorías. Sin duda, era una persona muy inquieta intelectualmente y capaz de argumentar con lógica las hipótesis en apariencia más extravagantes, dando la sensación de que siempre escribía dotado de un gran sentido común. La idea básica que caracteriza a todo su pensamiento es el cuestionamiento de la sociedad dirigida por profesionales-expertos-técnicos y la consecuente profesionalización de la enseñanza. Con esto se situó valientemente en un punto de vista que representó en su momento una 
crítica tanto a la política de los países capitalistas, como a la desarroIlada en los países comunistas. Así, leemos que afirma en una entrevista: "Creo haber podido observar que en cada campo hasta ahora analizado, el instrumento material de producción puede adquirir ciertas características meramente técnicas por las cuales impone, a toda sociedad que adopte este medio como instrumento de producción, unas relaciones sociales profundamente explotadoras y altamente injustas. Este es mi punto de partida" ${ }^{\prime 5^{5}}$.

Nuestro autor revisó los que consideró grandes mitos de nuestra civilización para propugnar lo que podríamos denominar una revitalización de la propia vida. Esta revitalización de la existencia pasa por aligerarla de los distintos corsés institucionales que, según él, la violentan. La ciencia, la escuela o la medicina, en cuanto saberes institucionalizados, imponen un corsé al entendimiento que anula la interacción humana espontánea y original. En definitiva, las instituciones no sólo no nos ayudan a vivir una vida mejor, sino que, enfatiza Illich, nos sustraen por completo la posibilidad de ella. Así lo expresa con toda claridad: "No somos capaces de concebir más que sistemas de hiper-instrumentalización para los hábitos sociales, adaptados a la lógica de la producción en masa. Casi hemos perdido la capacidad de soñar un mundo en donde la palabra se tome y se comparta, en donde nadie pueda limitar la crea- tividad del prójimo, en donde cada uno pueda cambiar la vida" ${ }^{6}$.

Además, la crítica de Illich a la escolarización guarda estrecha relación con la crítica que también hace al consumismo. Así lo afirma un editor de su obra y amigo suyo: "Detrás de las comprobaciones, rápidamente simplificadas por sus seguidores, como 'la escuela desescolariza', 'el hospital enferma', 'el automóvil obstruye la circulación', se encuentra una notable crítica al 'progreso' y a aquello que lo legitima, la satisfacción de las supuestas 'necesidades' ${ }^{\prime \prime}$. En efecto, Illich realiza un análisis y genealogía de las diversas necesidades que asumimos en nuestra época: "El estudio de la invención de las necesidades estandarizadas y válidas para todos ocupará a Ivan Illich durante varios años y lo obligará, en el transcurso de ellos, a establecer otras genealogías como las de "ser humano", "vida", "persona", "género", "salud", etc., de donde resulta una evolución en la historia de Occidente ${ }^{\prime \prime}$.

Desde luego, las propuestas de Illich tienen sentido dentro de una concepción específica del hombre que ya he avanzado con anterioridad. Para él, el ser humano es, fundamentalmente, persona libre que se realiza creando y colaborando con los demás. Nos muestra su entorno ideal en un mundo más austero y justo que nuestras actuales sociedades de consumo, en el que los seres humanos disfrutan de un mayor control sobre su destino vital. 
O sea, nos habla de personas que viven con menos comodidad material que en la sociedad consumista, pero que participan en su propia cultura, realizando su potencial de creatividad y libertad. Así, dice: "El hombre reencontrará la alegría de la sobriedad y de la austeridad reaprendiendo a depender del otro, en vez de convertirse en esclavo de la energía y de la burocracia todopoderosa" ${ }^{\prime \prime}$.

Illich argumenta que al ser humano no le es posible la felicidad en un mundo consumista: "Una sociedad que define el bien como la satisfacción máxima, por el mayor consumo de bienes y servicios industriales, del mayor número de gente, mutila en forma intolerable la autonomía de la persona" ${ }^{\prime 10}$. Para nuestro autor, "poco a poco las instituciones no sólo han conformado nuestra demanda, sino que también han dado forma a nuestra lógica; es decir, a nuestro sentido de la medida. Primero se pide lo que produce la institución, pronto se cree no poder vivir sin ello,"11.

En definitiva, las instituciones que indiscutiblemente nos han hecho la vida más cómoda en lo material constituyen un arma de doble filo, porque generan en todos nosotros una paralizante dependencia y pasividad. Nos acabamos acostumbrando a que ellas nos organicen y faciliten la vida, pagando el precio de acabar sometiéndonos a su lógica. Será desde esta convicción que llevará a cabo su crítica a la escolarización. Una crítica que, como hemos dicho, parte de una nueva manera de ver las cosas aparentemente más normales y habituales, del ejercicio de una mirada combativamente inocente.

\section{Razones para la desescolarización de la sociedad}

A I abordar Iván Illich directamente la institución escolar, con la explosiva ingenuidad que lo caracteriza, se esfuerza en mostrarnos que la transmisión del conocimiento y la cultura, que había discurrido durante siglos con espontaneidad vital fuera de la escuela y sin necesidad de ella, hoy ha quedado restringida al interior de las paredes del aula. Por eso, en cuanto resultado de un proceso histórico, resulta cuestionable la necesidad de ser educados escolarmente. No supone una necesidad absoluta ni tiene por qué implicar un bien.
Para él, haría falta elaborar una historia de la necesidad de educación (más que una historia de la educación). En esto se desmarca o matiza las concepciones usuales y el tipo de acercamiento que solemos llevar a cabo cuando analizamos la escuela y el desarrollo histórico de la educación. Como señala Antoni Tort: "[Illich] consideraba que la historia de la educación que se hace en el mundo sigue sin investigar cómo nace históricamente la necesidad de educación y sólo analiza modalidades educativas, sin cuestionarse la propia existencia de 
las instituciones y los sistemas. Creía que no hay suficientes estudios 'sobre' la educación, y que convendría analizar con más profundidad la historia de cómo emerge una realidad social en el seno de la cual la educación es percibida como una necesidad fundamental" ${ }^{12}$.

Iván Illich constata que el ecosistema específico de la escuela se halla lejos de un entorno natural en donde fluye la vida y seríamos personas. Este alejamiento se refleja, sintomáticamente, en una escisión de la cultura humana entre lo popular, por una parte, y lo académico o escolar, por otra. De modo que nuestro autor afirma que: "La existencia misma de escuelas obligatorias divide cualquier sociedad en dos ámbitos: ciertos lapsos, procesos, tratamientos y profesiones son 'académicos' y 'pedagógicos', y otros no lo son. Así, el poder de la escuela para dividir la realidad social no conoce límites: la educación se hace no terrenal, y el mundo se hace no educacional" ${ }^{13}$.

Siguiendo un símil del propio Illich, en la escuela se intenta regular la producción en masa de saber, mediante grados parecidos a los que la alquimia logra en su purificación de la materia. "Dentro del proceso alquimista, la educación se convierte en la búsqueda de aquello de donde nacerá un nuevo tipo de hombre, requerido por el medio, moldeado por la magia científica. Pero sea cual haya sido el precio pagado por las sucesivas generaciones, se reveló cada vez de nuevo que la mayoría de los alumnos no eran dignos de alcanzar los más altos grados de la iluminación, y era preciso excluirlos del juego, por ineptos, para llevar la 'verdadera' vida, ofrecida en ese mundo creado por el hombre" ${ }^{\prime 14}$. De este modo, la separación radical de lo vital y lo académico que se daría en la educación-alquimia sería paralelo a una nueva consecuencia perniciosa, desde el punto de vista de nuestro autor: la jerarquización de los seres humanos. Según su parecer, las relaciones jerárquicas y la división excluyente entre los seres humanos resultan gravemente malignas por lo que conllevan de incomunicación, de obstaculización del diálogo entre las personas. Es este un aspecto de su pensamiento que nos remite también a otros autores de la filosofía y la pedagogía del siglo XX: Fromm, Reich, Paulo Freire, A. S. Neill, etc. En esta línea, que entiende la felicidad como algo que requiere la "horizontalización" de las relaciones humanas $^{15}$, se inserta la perspectiva de Iván Illich.

Pero no sólo tenemos este gran inconveniente, sino que la escuela también prepararía para la sociedad consumista propia de nuestro tiempo, conformando ideológicamente para ello a los sujetos-educandos. Illich lo expresa a menudo de distintas formas: "La escuela es el rito de iniciación que conduce a una sociedad orientada al consumo progresivo de servicios cada vez más costosos e intangibles, una sociedad que confía en normas de valor de 
vigencia mundial, en una planificación en gran escala y a largo plazo, en la obsolescencia continua de sus mercancías, basada en el ethos estructural de mejoras interminables: la conversión constante de nuevas necesidades en demandas específicas para el consumo de satisfactores nuevos ${ }^{\prime \prime 16}$.

Como conclusión a partir de estas premisas, Illich argumenta que los problemas relacionados con la educación no se solucionarían con mejoras parciales, mayores inversiones, el uso de nuevas didácticas y ni siquiera con el fomento del trabajo cooperativo o el papel activo de los niños en el aula. El quid de la cuestión estribaría, según él, en comprender que el problema es la propia escuela, como promotora de los mencionados inconvenientes, que son consecuencia de lo que supone de ritualización y profesionalización del proceso de enseñanza-aprendizaje que inevitablemente conlleva. El malestar de la escuela reside justo en la suplantación de un proceso más sencillo y natural que ocurre fuera de ella. Como nos señala el pensador austriaco: "Lo principal del aprendizaje sobreviene casualmente, e incluso el aprendizaje más intencional no es el resultado de una instrucción programada"17.

Refiriéndose a quienes proponen mejoras dentro de la institución escolar, Illich afirma: "Creo que todos estos críticos yerran debido a que no toman en cuenta el aspecto ritual de la enseñanza, como lo he llamado en otro trabajo y que en éste me propongo denominar el 'currículum oculto', la estructura que sirve de base de sustento a lo que se conoce como 'efecto de certificación'"'18. Es decir, la escuela hace y enseña lo contrario de lo que afirma hacer y enseñar. No es el currículum oficial el que describe lo que principalmente aprende el niño en ella, sino el currículum oculto: "Todos los niños aprenden, gracias al currículum oculto, que el conocimiento económicamente valioso es el resultado de la enseñanza institucionalizada y que los títulos sociales son resultado del rango que se ocupa en el proceso burocrático. Así, el currículum oculto transforma el currículum visible en una mercancía y hace de su adquisición la forma de riqueza más segura" ${ }^{19}$.

A pesar de todas las reformas posibles, a juicio de Illich, el conocimiento se acaba convirtiendo, en la escuela y por ella, en una mercancía que supone una suerte de posesión y riqueza material para quien la obtiene. Aquí tenemos la iniciación en la visión mercantil del mundo como terreno para la posesión y el intercambio económico de las cosas (en el contexto de una naturaleza y mundo cosificados, cabría matizar, en la que todo se convierte en objetos para ser poseídos). "La interpretación de la necesidad de aprender como una demanda de escolaridad y la transformación de la cualidad de crecer y desarrollarse en la etiqueta de una educación profesional convierten el significado de la palabra conocimiento, de un término 
que indica intimidad, intercambio con otras personas y experiencia vital, en uno para designar productos profesionalmente empacados, títulos cotizables en el mercado y valores abstractos. La escuela ha ayudado a dar alas a tal interpretación ${ }^{\prime 20}$.

Por todo ello, la consecuencia del paso por la escuela sería una suerte de alejamiento del ser humano de su propia felicidad, basada desde esta perspectiva crítica, en la fraternidad, resultando, pues, una cierta mutilación, como nuestro autor subraya en numerosas ocasiones: "Una expansión del concepto de alienación podría permitirnos ver que en una economía fundada en la prestación de servicios, el hombre es separado de lo que puede hacer, lo mismo que de lo que puede producir; que ha entregado su mente y su corazón a un tratamiento mutilante en forma más completa de lo que ha vendido los frutos de su trabajo ${ }^{\prime 21}$.

El sujeto así alienado vive la reglamentación del saber como una opresión anónima, cuya fuente le resulta invisible e imposible de señalar. Es la consecuencia de la sociedad del experto (tecnocracia) en la que los ciudadanos han aprendido inconscientemente que su acceso a la realidad tiene que ser mediatizado: "El consumidor de conocimientos precocinados aprende a reaccionar ante el conocimiento que ha adquirido más que ante la realidad, de la cual un grupo de expertos lo ha abstraído. Su acceso a la realidad es controlado siempre por un terapeuta, y, si el alumno acepta tal control como cosa natural, su cosmovisión se convierte en algo higiénico y neutral y él en una persona políticamente impotente $\mathrm{e}^{\prime \prime 22}$.

A continuación, voy a comparar estas ideas de Illich con algunas pedagogías radicales que, sin llegar tal vez a sus conclusiones extremas, pueden enriquecer la discusión sobre el papel de la escuela y las posibles alternativas que cabría imaginar, que es lo que como he dicho pretendo con este trabajo.

\section{Autoritarismo y educación: la perspectiva de la pedagogía no directiva}

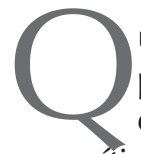

ue la educación escolar puede tener un potente efecto alienador no ha sido una crítica tan sólo de los autores de la desescolarización ${ }^{23}$. También lo encontramos, con argumentos más o menos próximos, en Ferrière ${ }^{24}$, la educación liberadora de Paulo Frei- $\mathrm{re}^{25}$ y la pedagogía y la praxis de la escuela "Summerhill" que fundara el escocés A. S. Neill ${ }^{26}$. En todos ellos encontramos destacado el hecho de que en las formas más directivas de educación, la actividad y la creatividad se convierten en privilegio exclusivo del experto, en cuya auto- 
ridad descansa el conocimiento y la transmisión del mismo. Así, educar llega a ser una actividad unidireccional en la que el educando adopta un comportamiento pasivo y es "dirigido" en el proceso de su propio crecimiento y aprendizaje.

Desde luego, cuando estos pedagogos cuestionan la autoridad del maestro, a menudo tienen en mente una concepción de escuela autoritaria o directiva, que no siempre se corresponde con la idea común que se suele tener del autoritarismo. Es preciso resaltarlo. No siempre el autoritarismo que ellos critican equivale al expresado por el lema "la letra con sangre entra". De hecho, para muchos de ellos, "las escuelas del siglo XX han desarrollado un tipo de autoridad anónima que prepara a los estudiantes para la manipulación a manos de una sociedad propagandista y burocrática. La escuela tradicional era un ejemplo perfecto de autoridad abierta: el maestro se enfrentaba directamente a los estudiantes con su propio poder, y los estudiantes siempre eran conscientes de dónde partía el poder. El aspecto favorable de esta situación era que si los estudiantes deseaban rebelarse y pedir su libertad, podían identificar la fuente del poder y reaccionar ante ella. En el siglo XX, se introdujeron en las escuelas formas anónimas de autoridad por medio de técnicas psicológicas más sofisticadas. Estas formas de control han hecho mucho más difíciles la comprensión del hecho de la manipulación y la identificación de la fuente de control ${ }^{\prime 27}$.
En efecto, sobre el concepto de "autoridad" hay bastante que puntualizar. En este sentido, Erich Fromm, en su prólogo al primer libro que escribió Neill sobre Summerhill, se pregunta si es un error proponer una educación que no emplee la fuerza. El aparente fracaso de la educación permisiva y la escuela carente de disciplina nos puede conducir a rechazar la ausencia de autoridad sancionadora. Pero la cuestión es más sutil. Así, precisa Fromm: "Yo creo que la idea de libertad para los niños no era errónea, pero sí que la idea de la libertad ha sido pervertida casi siempre. Para examinar con claridad este asunto, debemos empezar por comprender la naturaleza de la libertad, y para ello debemos distinguir entre autoridad evidente y autoridad anónima" ${ }^{28}$.

Su reflexión conduce a una definición de la libertad que se relaciona con la psique y la vida afectiva. En El miedo a la libertad ${ }^{29}$ explica cómo la libertad que surge en el proceso de individuación puede constituir una pesada carga para el sujeto, que pagaría como precio el padecimiento del amargo sentimiento de la separatidad. Así pues, la libertad puede asustar al hombre, porque teme hallarse a solas con las riendas del propio destino, verse como solitario responsable de sí mismo. Con el fin de evitar esa angustiosa soledad, los seres humanos buscan maneras de regresar a la unidad primigenia que se vivía en el útero materno. Es de- 
cir, intentan regresar a la existencia anterior al surgimiento del individuo autónomo.

Una forma recurrente de regresar a este paraíso originario ha sido, en los pueblos y en los individuos, el sometimiento más o menos consciente a una autoridad, cobijándose bajo su manto y amparo, de modo que decae el peso que la libertad coloca sobre el sujeto. $Y$ es a partir de esta profunda necesidad cómo se constituye y recibe su fuerza la "autoridad anónima". El autoritarismo, con uno u otro matiz, se aprovecha de la necesidad de "guía" producida por el miedo que la libertad puede generar en los seres humanos.

La autoridad anónima es mucho más penetrante y eficaz que la coerción ejercida por la fuerza. El suyo es un poder basado en los temores asociados con la condición humana, o sea, en los miedos atávicos que los hombres soportan como precio de su libertad y autonomía. En palabras de Fromm: "La autoridad anónima tiende a ocultar que se emplea la fuerza. La autoridad anónima finge que no hay autoridad, que todo se hace con el consentimiento del individuo. Mientras que el maestro del pasado le decía a Juanito: 'Debes hacer esto. Si no, te castigaré', el maestro de hoy dice: 'Estoy seguro de que te gustará hacer esto'. Aquí la sanción para la desobediencia no es el castigo corporal, sino el gesto ceñudo del padre o, lo que es peor, la sensación de no estar 'ajustado', de no obrar como obra de la mayoría.
La autoridad evidente empleaba la fuerza física; la autoridad anónima emplea el manejo psíquico" ${ }^{\prime 30}$. Y la autoridad así ejercida es mucho más efectiva.

Según Fromm, el moldeamiento que va ejerciendo esa autoridad anónima obedecería en último término a la lógica del capitalismo consumista, porque satisface la necesidad que tiene el sistema económico de crear seres adecuados al mismo, individuos que crean querer consumir cada vez más. "Nuestro sistema ha de crear hombres de gustos uniformes, hombres que puedan ser influidos fácilmente, hombres cuyas necesidades puedan preverse. Nuestro sistema necesita hombres que se sientan libres e independientes, pero que, sin embargo, hagan lo que se espera de ellos, hombres que encajen en el mecanismo social sin fricciones $^{\prime{ }^{\prime 31}}$. O sea, en el mundo capitalista de consumo la autoridad es una autoridad sin nombre que practica la persuasión y la sugestión antes que la fuerza, para conseguir un tipo específico de persona que viene requerido por el sistema económico.

Hemos de tener presente que la violencia por parte de los alumnos también participa de una lógica autoritaria. Porque si el niño hace todo lo que quiere, no existe libertad real, sino una degeneración de las relaciones humanas y la educación que Neill denomina "libertinaje" o "licencia". De algún modo, el niño se ha sentido esclavo, ha percibido que se le ha conducido sutilmente 
contra sí mismo, hacia valores extraños, etc. Ha aprendido que las relaciones humanas consisten en abusar unos de otros. Y si puede, abusa él también. Ha interiorizado la lógica del poder y el dominio.

Para que se diese la auténtica libertad, el niño no puede carecer de derechos, pero tampoco debe tenerlos todos. Es una sutil línea que se expresa en el elocuente y conocido lema que enuncia Neill: "La libertad significa hacer lo que se quiera mientras no se invada la libertad de los demás. El resultado es la autodisciplina ${ }^{\prime{ }^{32}}$. La libertad requiere, por tanto, el aprendizaje de la propia responsabilidad y la convivencia. Con la claridad que lo caracteriza, Neill (1999) lo expresa: "El autocontrol implica la capacidad para pensar en los demás, para respetar el derecho de los demás (...). El hombre autocontrolado no se sienta a la mesa con otros comensales y se sirve la mitad del contenido de la ensaladera" ${ }^{\prime 33}$. Y el niño, para ser libre, debe aprender este autocontrol que parte de la estimación solidaria del otro. Éste es el objetivo supremo de escuelas como Summerhill.

La conexión entre la educación en la escuela y la transformación crítica de la sociedad es enfatizada por Neill. Las palabras del pedagogo escocés en la introducción a su libro más conocido son bastante expresivas: "Todos los crímenes, todos los odios, todas las guerras, pueden reducirse a infelicidad. Este libro intenta hacer ver cómo nace la infelicidad, cómo arruina las vidas humanas, y cómo pueden criarse los niños de manera que no se presente nunca una proporción crecida de esa infelicidad" ${ }^{\prime 34}$. Más adelante, señala: "La civilización está enferma y es desgraciada, y yo sostengo que la raíz de todo ello es la familia sin libertad" ${ }^{35}$, y "no hay nunca niños problema; sólo hay padres problema. Quizás fuera mejor decir que sólo hay una humanidad problema ${ }^{\prime \prime 36}$. No es posible, desde esta perspectiva, diferenciar tajantemente la escuela y la sociedad. Hay una conexión imposible de desligar y que se debe contemplar a la hora de desarrollar, por ejemplo, diagnósticos o terapias para el niño. Por esto mismo, toda curación debe considerar la salud o la enfermedad de la sociedad al completo, en la línea del pensamiento y la psicología, también, de Erich Fromm o Wilhelm Reich $^{37}$.

Pero Iván Illich Ilega más lejos aún. Como afirma el estudioso de su obra Antoni Tort: "Para Illich, no es posible convertir las escuelas, instituciones burocratizadas, actuales y manipulativas, en otras de carácter convivial, humanizadoras, donde las personas actúen autónomamente. Las propuestas coetáneas a la desescolarización, desde el auge de Summerhill hasta la pedagogía institucional, en ningún caso suponen, para Illich, un preludio de revolución educativa" ${ }^{38}$. El controvertido autor austriaco subraya la necesidad de no dejarnos seducir por reformas de la escuela que no 
cuestionan a la propia institución escolar. La enfermedad es ella misma. Mientras exista escuela, por más libre que sea $-\mathrm{y}$ en esto nuestro autor supera con claridad los planteamientos de Neill-, se sigue generando una personalidad dependiente, un espíritu esclavo. Porque las formas solapadas de autoritarismo son imposibles de eliminar de toda educación impartida bajo el modelo "profesor-alumno". La escuela inevitablemente crea adicción y enseña la necesidad de ella misma. El niño educado en escuelas como Summerhill puede demandar toda la vida la escuela "libre" en la que se educó, en una sociedad que, además, marcha por derroteros brutalmente contrarios. Como afirma Illich: "Los graduados de la escuela libre son fácilmente reducidos a la impotencia al enfrentarse a la vida en una sociedad que no se parece en nada a los invernaderos en que han sido cultivados ${ }^{\prime \prime 39}$.

Para Illich resulta fundamental entender la escuela como el producto de una forma específica (y criticable) de sociedad humana, concluyendo que es necesaria una transformación profunda y general que abarque toda la cultura humana y acabe superando la propia idea de "escuela" o "escolarización".

\section{La siempre inacabada utopía de la sociedad desescolarizada}

L

a utopía que, como he ido avanzando en líneas anteriores, versivo de Illich es la de una cultura en la que todos los seres humanos seamos protagonistas y artífices. Sus propuestas persiguen la devolución a las personas de su capacidad natural de crear cultura y de participar en ella. Esta es la nota definitoria del sujeto crítico, como también describen Giroux y McLaren: "Ser crítico (...) significa desechar cualquier distancia cognitiva puramente contemplativa, sobre y por encima del mundo, pero para afrontar la contingencia del presente con la esperanza radical" ${ }^{\prime 4}$. El enfoque crítico de la educación aspira a una praxis educativa en la que no haya escisión entre el pensamiento y la acción.
Así, podemos leer: "Me estoy refiriendo aquí acerca de una praxis en la cual el sujeto cognoscente es un sujeto actuante, una praxis en la cual asumimos la responsabilidad de la historia y de una visión del mundo que 'aún no es ${ }^{\prime \prime \prime}{ }^{41}$.

La educación escolar ha complicado las cosas, desde la perspectiva del autor austriaco, reglamentando e institucionalizando el mecanismo natural de la continua re-creación de cultura. El intento de Illich consiste en la recuperación de la horizontalidad entre los seres humanos, perdida por culpa de la escolarización del modo que hemos explicado en líneas anteriores, de manera que conectemos de nuevo con la transitividad que nos es propia ${ }^{42}$. 
Como hemos visto, Illich subraya la función esencialmente ideológica de la institución escolar, en la medida en que contribuye a la interiorización de la verticalidad que caracteriza a nuestra sociedad de consumo, fortaleciéndola y justificándola. Los títulos expedidos en los distintos niveles de la educación formal van catalogando a los individuos, que sienten el conocimiento como una posesión que otorga prestigio, excluyendo de la sabiduría a quien no los posee y absolutizando su ignorancia. Así, afirma: "Una vez que se ha escolarizado a las personas con la idea de que los valores pueden producirse y medirse, tienden a aceptar toda clase de clasificaciones jerárquicas" ${ }^{\prime 43}$. En este sentido, se puede entender que existe una forma escolar de ver y entender el mundo; es decir, hay una mentalidad escolar cuyo aprendizaje resulta la principal función oculta de la escuela.

La consecuencia de la escolarización, desde la perspectiva de Illich, resulta atroz. Porque a la vez que el sujeto educando aprende a integrarse en la sociedad estratificada y de consumo, emprende un camino de honda infelicidad que lo aleja de sí mismo y frustra sus verdaderas necesidades: "La escuela hace a la alienación preparatoria para la vida, privando así a la educación de realidad y al trabajo de creatividad. La escuela prepara para la alienante institucionalización de la vida al enseñar la necesidad de ser enseñado. Una vez que se aprende esta lección, la gente pierde su incentivo para desarrollarse con independencia; ya no encuentra atractivos en relacionarse y se cierra a las sorpresas que la vida ofrece cuando no está predeterminada por la definición institucional" ${ }^{44}$.

Las alternativas de Illich a la escuela, que se hallan esbozadas en sus escritos, pretenden reubicar la educación en su dinamismo y espontaneidad $^{45}$. Persiguen devolver a la relación educativa su naturaleza de vinculación grata y creativa de los seres humanos entre sí. En general, en palabras de Antoni Tort, Illich propugna "tramas o redes educacionales que aumenten la oportunidad de que cada cual transforme cada momento de sus vidas en un momento de aprendizaje. La transferencia de la responsabilidad de educación hacia las instituciones, señalaba, no deja de ser un suicidio espiritual" ${ }^{46}$. Todas sus propuestas, por muy descabelladas que parezcan, se comprenden desde esta idea motriz. Propósito que también puede definirse, según nos esclarece la lectura de uno de sus libros más cercanos en el tiempo ${ }^{47}$, como devolver al ciudadano su espacio vital, donde él pueda desarrollarse y ser persona. Se trata de una reivindicación de la intimidad y del espacio individual donde el sujeto es dueño y creador, que se contrapone al espacio aséptico y racionalizado de las ciudades contemporáneas (y de la escuela) que nos invade ${ }^{48}$. En los colegios el ámbito impersonal y mecánico se apodera de los su- 
jetos, que dejan de serlo y que se ven obligados a someterse a una racionalidad ajena, la cual parece adquirir vida propia e imponerse a los hombres estableciendo sus reglas.

En la definición de educación que a veces sugiere se esclarece esto que vengo diciendo. En cierta ocasión, debatiendo con Paulo Freire, Illich propone la siguiente descripción de lo que se entiende implícitamente por "educación": "Educación -lo que hoy se llama educación - es esencialmente una producción planeada de aprendizaje en otro. Y si no les gusta la palabra 'producción', entonces, provocación planeada de libertad en otro - como opuesta al espontáneo, al autónomo descubrimiento que surge del encuentro entre usted y yo ${ }^{\prime \prime 4}$. Esta definición no implica solamente a la denominada "educación formal", sino que en muchos aspectos, también a la "educación informal" y a la "educación no formal". En realidad, se trata de algo más básico que podíamos denominar "mentalidad escolar". Desde ésta, cabe entender, por ejemplo, la figura de un ministro de educación, que para Illich resulta ilógica. "Llamo aquí ministro de educación a un personaje de fábula, quiero decir, a la institución que puede determinar qué cosa van a hacer el maestro y el alumno cuando estén juntos en la clase $^{\prime \prime 50}$. En esto se desmarca tanto de la visión conservadora y liberal como de la izquierda marxista, y constituye el aspecto más aprove- chable de su crítica, a juicio de Fernández Enguita: "Ese fue el gran acierto de Illich: captar el hecho de que las profesiones y sus clientelas dependientes (a la vez que la estratificación social del trabajo de acuerdo con la cualificación) forman parte de otra relación de poder, que son otro pilar de desigualdad, sólo que basado en la distribución asimétrica del conocimiento en vez de en los medios de producción o el mando sobre las personas ${ }^{\prime \prime 1}$. No obstante, este mismo autor hace un balance finalmente negativo de la visión del austriaco y de toda crítica a las instituciones (o "burocracias", en palabras de Illich): "Illich nos ayudó a abrir los ojos ante la dinámica opresiva inherente a la institución escolar y los intereses corporativos de la profesión, pero sin proponer otra respuesta que el retorno imposible a un pasado inexistente. No era una utopía, sino una ucronía. La tarea de quienes creen posible otra educación no estriba en imaginar un implausible mundo desinstitucionalizado, sino en democratizar de arriba abajo unas instituciones de las que no sabríamos prescindir" ${ }^{\prime 2}$.

La crítica de Illich es, en realidad, una crítica a las instituciones que cuadriculan la existencia humana apropiándose de ella. Como afirma él mismo: "Al insistir en un 'espacio' interior me defiendo contra la geometrización de mi intimidad, contra su reducción a una noción algebraica equivalente a un espacio exterior que ha sido reducido a di- 
mensiones cartesianas" ${ }^{\prime \prime 3}$. Pretende esbozar, en este sentido, una sociedad que facilite la expresión y la participación de todas las personas en espacios culturales aptos para ello. Y en todo esto no hace sino enlazar con una corriente autocrítica de la propia Modernidad. En efecto, la teoría desescolarizadora es, como los movimientos contraculturales de los años sesenta y setenta, una alternativa con raíces en la propia Modernidad, en sus planteamientos más radicales y autocríticos surgidos ya en el propio siglo XVIII. Creo que, por tanto, Illich es en realidad heredero de una Ilustración que se opone a las consecuencias alienantes de la propia Ilustración. Cuando dialogamos con Illich, lo hacemos con uno de los últimos pensadores utópicos que, desde luego, constituyen una herencia de la modernidad ilustrada, en cuanto razón que se cuestiona a sí misma.

En cualquier caso, la lectura de Illich resulta un ejercicio refrescante y gozoso porque nos transmite esperanza, incitándonos a construir una cultura impregnada de utopía. El hecho de que exista una visión como la suya nos dota de un bello horizonte hacia el que orientarnos como educadores. Qué duda cabe que nutrir con su lectura nuestra imaginación nos puede ayudar a entender la educación. Pero, insisto, hemos de tener muy presente que él nunca pretendió decirnos con exactitud qué debemos hacer. Lo cual, aunque se ha visto como defecto, creo que es su mayor virtud. Lo que ocurre es que nunca quiso trazar un plano detallado de algo Ilamado "Utopía" ni decirle irrespetuosamente a nuestros hijos lo que tendrán que hacer. Él mismo lo expresa así: "De nada me serviría ofrecer una ficción detallada de la sociedad futura. Quiero dar una guía para la acción y dejar libre curso a la imaginación. La vida dentro de una sociedad convivencial y moderna nos reserva sorpresas que sobrepasan nuestra imaginación y nuestra esperanza. No propongo una utopía normativa, sino las condiciones formales de un procedimiento que permita a cada colectividad elegir continuamente su utopía realizable $\mathrm{e}^{\prime{ }^{54}}$. Así pues, como última reflexión, deseo resaltar el profundo respeto a los seres humanos que esto muestra. La frescura y originalidad de la mirada de Ivan Illich le lleva a concebir la educación como antesala de un futuro que prefirió donar, respetuosamente, a las personas que vendrán. 
REFERENCIAS BIBLIOGRÁFICAS

Boff, Leonardo: El cuidado esencial. Ética de lo humano. Compasión por la tierra, Madrid, Trotta, 2002.

Fernández Enguita, M.: "Una reconsideración", Cuadernos de pedagogía, 323 (2003), pp. 77-80.

Ferrière, A.: La escuela activa, Barcelona, Herder, 1982.

Freire, P.: La educación como práctica de la libertad, Madrid, Siglo XXI, 1989.

- Pedagogía del oprimido, Madrid, Siglo XXI, 1992.

Fromm, E.: El miedo a la libertad, Buenos Aires, Paidós, 1976.

Prólogo, en: Neill A. S.: Summerhill. Un punto de vista radical sobre la educación de los niños, Madrid, Fondo de Cultura Económica, 1994, pp. 9-15.

Giroux, H., y McLaren, P.: Sociedad, cultura y educación, Madrid, Miño y Dávila, 1998.

Goodman, P.: La des-educación obligatoria, Barcelona, Fontanella, 1976.

Holt, J.: El fracaso de la escuela, Madrid, Alianza, 1982.

Illich, I.: La sociedad desescolarizada, Barcelona, Barral, 1974.

"Conversando con Iván Illich", Cuadernos de pedagogía, 7 (1975), pp. 16-23.
La convivencialidad, Barcelona, Barral, 1978.

$\mathrm{H}_{2} \mathrm{O}$ y las aguas del olvido, Madrid, Cátedra, 1989.

y Freire, P.: Diálogo, Buenos Aires, Búsqueda, 1975.

Gintis, H., Greer, C., Postman, N., Gross, R., Fairfield, R. P., et al.: Un mundo sin escuelas, México, Nueva Imagen, 1977.

Neill, A. S.: Summerhill. Un punto de vista radical sobre la educación de los niños, Madrid, Fondo de Cultura Económica, 1994.

Hijos en libertad, Barcelona, Altaya, 1999.

Paquot, T. : "La résistance selon Ivan Illich", Le monde diplomatique, janvier (2003), p. 28. (Versión castellana de la edición española)

Reimer, E.: La escuela ha muerto. Alternativas en materia de educación, Barcelona, Guadarrama, 1981.

Santos, M: "La tolerancia en la escuela: el modelo pedagógico socrático", Revista de Ciencias de la Educación, 194 (2003) pp. 157-173.

"Antecedentes del valor educativo 'tolerancia'", Revista española de pedagogía, 231 (2005), pp. 223-238.

"De la verticalidad a la horizontalidad. Reflexiones para 


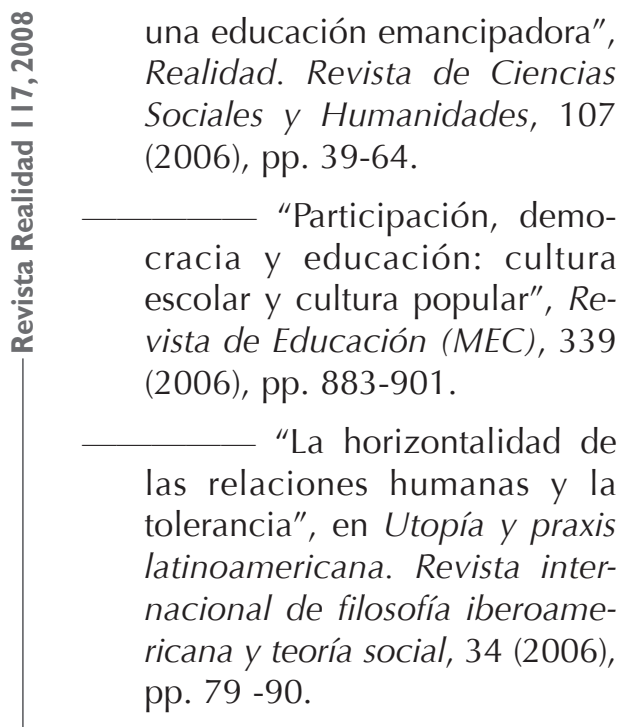

\section{NoTAS}

1 Tort, A.: "Ivan Illich: la desescolarización o la educación sin la escuela", en: Trilla, J. (coord.): El legado pedagógico del siglo XX para la escuela del siglo XXI, Barcelona, Graó, 2002, pp. 271-296. p. 295.

2 De su especial vínculo con América Latina, más allá del mero hecho biográfico de haberse ubicado primero en Puerto Rico y, sobre todo, México, da fe recientemente Leonardo Boff, quien lo considera "uno de los grandes profetas latinoamericanos”, por su concepto de "convivencialidad”. Cfr. Boff, Leonardo: El cuidado esencial. Ética de lo humano. Compasión por la tierra, Madrid, Trotta, 2002, pp. 100-103. Su discurso, que pretende ser universal, parte y se elabora desde la realidad latinoamericana. Como ha ocurrido con tantos, América Latina le dio importantes claves, posiblemente,
Spring, J.: Introducción a la educación radical, Madrid, Akal, 1987.

Taberner, J. y Rojas, C.: Marcuse, Fromm, Reich: El freudomarxismo, Madrid, Cincel, 1988.

Tort, A.: "Ivan Illich: la desescolarización o la educación sin la escuela", en: Trilla, J. (coord.): El legado pedagógico del siglo $X X$ para la escuela del siglo XXI, Barcelona, Graó, 2002, pp. 271-296

"Los silencios y las palabras de Iván Illich", Cuadernos de pedagogía, 323 (2003), pp. 81-83.

para comprender, interpretar y cuestionar el tipo de sociedad (global) en que nos hallamos todos.

3 Como es el caso de la inocencia (irónica) de Sócrates: Vid. Santos, Marcos: "La tolerancia en la escuela: el modelo pedagógico socrático”, Revista de Ciencias de la Educación, 194 (2003) pp. 157-173; Id.: "Antecedentes del valor educativo 'tolerancia'”, Revista Española de Pedagogía, 231 (2005), pp. 223-238. Según es conocido, el filósofo ateniense adoptaba una posición ingenua que, irónicamente, le conducía a preguntar a los "sabios" lo que él mismo afirmaba no saber, para acabar desmontando los prejuicios y falsas certezas de sus interlocutores. Esta acción demoledora de su pedagogía es la que, de un modo u otro, creo que se puede identificar con Illich. Las cuestiones planteadas por 
el austriaco bien puede decirse que ejercen un efecto similar en quienes nos consideramos sus interlocutores.

4 Illich, I.: "Conversando con Iván Illich”, Cuadernos de pedagogía, 7 (1975), pp. 16-23. p. 17.

5 Ibid. P. 16.

6 I. Illich, I.: La convivencialidad, Barcelona, Barral, 1978, pp. 32-33.

7 Paquot, T. : "La résistance selon Ivan Illich", Le monde diplomatique, enero de 2003, p. 28. (Versión castellana de la edición española)

8 Idem.

$9 \quad$ Illich, I.: Op. Cit., 1978, p. 31.

10 Ibid., p. 29.

11 Ibid., p. 37.

12 Tort, Antoni: "Los silencios y las palabras de Iván Illich”, Cuadernos de pedagogía, 323 (2003), pp. 81-83. p. 81.

$13 \quad$ Illich, I.: (1974) La sociedad desescolarizada, Barcelona, Barral, 1974, p. 39.

$14 \quad$ Illich, I.: Op. Cit., 1978, p. 38.

15 Vid. Santos, M.: "De la verticalidad a la horizontalidad. Reflexiones para una educación emancipadora”, Realidad. Revista de Ciencias Sociales y Humanidades, 107 (2006), pp. 39-64; Id.: "La horizontalidad de las relaciones humanas y la tolerancia”, Utopía y praxis latinoamericana. Revista internacional de filosofía iberoamericana y teoría social, 34 (2006), pp. 79 -90.

16 Illich, I., Gintis, H., Greer, C., Postman, N., Gross, R., Fairfield, R. P., et al.: (1977). Un mundo sin escue-

las, México, Nueva Imagen, 1977, p. 15.

Illich, I.: Op. Cit., 1974, p. 25.

Illich, I., Gintis, H., Greer, C., Postman, N., Gross, R., Fairfield, R. P., et al.,: Op. Cit., 1977, p. 17.

Ibid., pp. 18-19.

Ibid., p. 20.

Ibid., p. 21.

Ibid., p. 29.

Como puede comprobarse en el contenido de sus obras principales, vg. Goodman, Paul: La des-educación obligatoria, Barcelona, Fontanella, 1976; Holt, John: El fracaso de la escuela, Madrid, Alianza, 1982; Reimer, Everett: La escuela ha muerto. Alternativas en materia de educación, Barcelona, Guadarrama, 1981.

Cfr. Ferrière, A.: La escuela activa, Barcelona, Herder, 1982.

Cfr. Freire, Paulo: Pedagogía del oprimido, Madrid, Siglo XXI, 1992.

Cfr. Neill, A. S.: Summerhill. Un punto de vista radical sobre la educación de los niños, Madrid, Fondo de Cultura Económica, 1994.

Spring, J.: Introducción a la educación radical, Madrid, Akal, 1987, p. 31.

28 Fromm, Erich: Prólogo, en: Neill, A. S.: Summerhill, Un punto de vista radical sobre la educación de los niños, Madrid, Fondo de Cultura Económica, 1994, pp. 9-15. p. 9.

Fromm, E.: El miedo a la libertad, Buenos Aires, Paidós, 1976.

Fromm, E.: Op. Cit., 1994, p. 10.

Idem. 


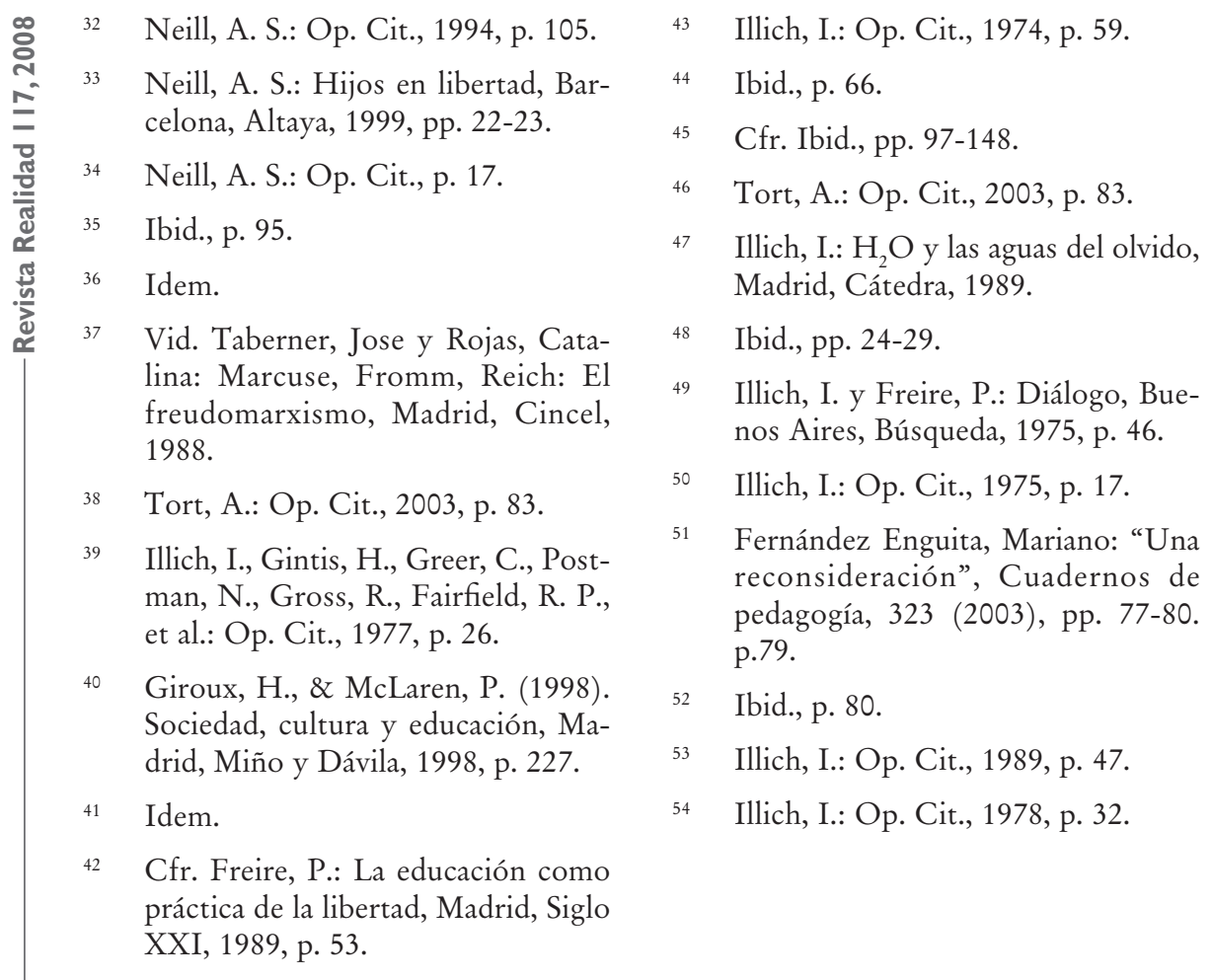

